\title{
Development and validation of a reliable method for studying the distribution pattern for opiates metabolites in brain
}

\author{
Katia Guerrini ${ }^{a}$, Antonella Argo $^{b}$, Cristina Borroni $^{a}$, Daria Catalano ${ }^{a}$, Lucia Dell'Acqua ${ }^{a}$, Fiorenza Farè ${ }^{a}$, \\ Paolo Procaccianti ${ }^{\mathrm{b}}$, Gabriella Roda ${ }^{\mathrm{a}, *}$, Veniero Gambaro ${ }^{\mathrm{a}}$ \\ a Dipartimento di Scienze Farmaceutiche "Pietro Pratesi”, Università degli Studi di Milano, Via Mangiagalli 25, 20133 Milano, Italy \\ ${ }^{\mathrm{b}}$ Istituto di Medicina Legale e delle Assicurazioni Policlinico Universitario, Via del Vespro n. 129, 90127 Palermo, Italy
}

\section{A R T I C L E I N F O}

Article history:

Received 18 November 2011

Received in revised form 30 March 2012

Accepted 2 April 2012

Available online 7 April 2012

\section{Keywords:}

Heroin

Morphine

Codeine

Post-mortem brain specimen

\begin{abstract}
A B S T R A C T
Brain distribution pattern of "street" heroin metabolites (morphine and codeine) was investigated in two fatalities due to "acute narcotism". A suitable sample pretreatment prior to solid-phase-extraction was developed to achieve a good recovery of the analytes and to eliminate the interfering species. After derivatization with MSTFA, samples were analyzed by GC/MS. Specificity, accuracy, precision and linearity of the method were evaluated; LOD and LOQ were, respectively, $10 \mathrm{ng} / 25 \mathrm{ng}$ for morphine and $5 \mathrm{ng} / 10 \mathrm{ng}$ for codeine.

This method was applied to the analysis of six brain areas (hippocampus, frontal lobe, occipital lobe, nuclei, bulb and pons) coming from two cases of heroin-related deaths. No evidence of accumulation of metabolites in a specific brain region was found.
\end{abstract}

(C) 2012 Elsevier B.V. All rights reserved.

\section{Introduction}

After intravenous assumption, heroin quickly crosses the bloodbrain barrier to produce a rapid onset of action. However, heroin is rapidly hydrolyzed to 6-monoacetylmorphine (6-MAM) and then to morphine (Fig. 1), which is in turn metabolized mainly (98\%) via conjugation with glucuronic acid at its 3 - and 6-positions to form morphine-3- $\beta$-D-glucuronide and morphine-6- $\beta$-D-glucuronide. Morphine-glucuronides are hydrophylic compounds, which are mainly excreted in urine and, in minor quantities, in bile.

Since heroin plasma half-life is very short, it is commonly held that morphine and 6-MAM are responsible for the protracted pharmacological actions of heroin and, moreover, can be detected in biological specimens after heroin assumption [1].

Furthermore, "street heroin" usually contains a 5-10\% of acetylcodeine, as impurity deriving from the synthesis, which in the body is metabolized to codeine, so that traces of codeine (Fig. 1) and of its metabolites can be found in heroin users' urine [2].

The concentration of drugs in blood [3], which are susceptible to rapid chemical and metabolic hydrolysis, does not always reflect drug concentration at the site of action, especially in the case of supposed death for heroin overdose, because post-mortem

\footnotetext{
* Corresponding author. Tel.: +39 02 50319328; fax: +39 0250319359.

E-mail address: gabriella.roda@unimi.it (G. Roda).
}

redistribution or drug instability can result in misleading variations of plasmatic drug levels [4].

Direct measurements of heroin metabolites concentrations in the brain are useful in post-mortem forensic toxicology to substantiate fatal overdoses [5]. Brain samples show several advantages respect to other specimens as concerns psychoactive drugs, because brain is an isolate compartment, endowed with lower metabolic activity, resulting in slower decomposition and delayed process of putrefaction [6,7].

Moreover, drugs of abuse exert their effects via the central nervous system, so that it can be assumed that the encephalic concentration of these drugs, measured in post-mortem specimens, is close or equal to their peri-mortem concentration at their site of action [8].

Although the advantages of brain samples in determining fatal overdoses are obvious, sampling of the brain is crucial and demands particular care; to minimize degradation, specimens should be analyzed as soon as possible. Furthermore, appropriate sample preparation is one of the most important pre-requisite for the successful identification and quantification of psychoactive drugs in brain specimens, eliminating interfering species such as proteins and lipids. To this end several methods were proposed ranging from liquid/liquid extraction [9-12] to solid phase extraction (SPE) [5,13-15] and several detection and quantification techniques were applied, based on liquid chromatography-mass spectrometry (LC/MS) [15-17] or gas chromatography-mass spectrometry (GC/MS) $[3,4,17,18]$. 
<smiles>C[C@@H]1Cc2ccc(O)c3c2[C@]2(C=C[C@H](O)[C@@H]2O3)CCN1C</smiles>

Morphine

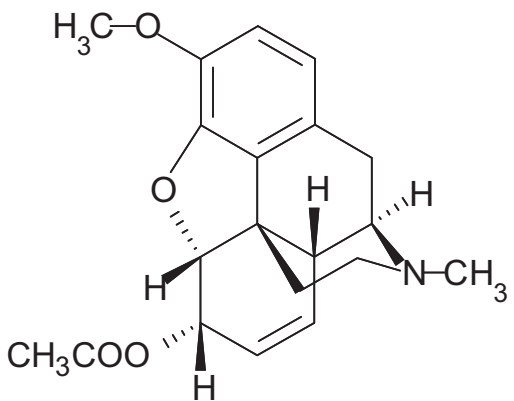

Acetylcodeine

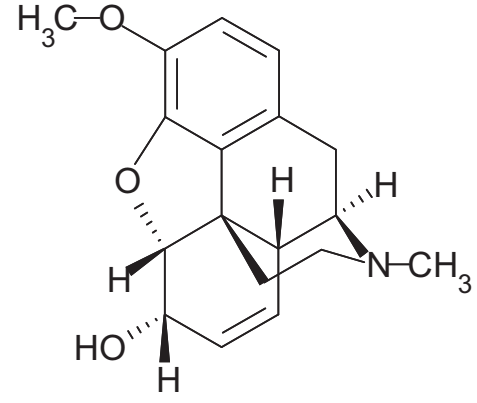

Codeine<smiles>CC(=O)O[C@H]1C=C[C@H]2CN(C)[C@H]3Cc4ccc(O)c5c4[C@]32C[C@H]1C5</smiles>

6-MAM

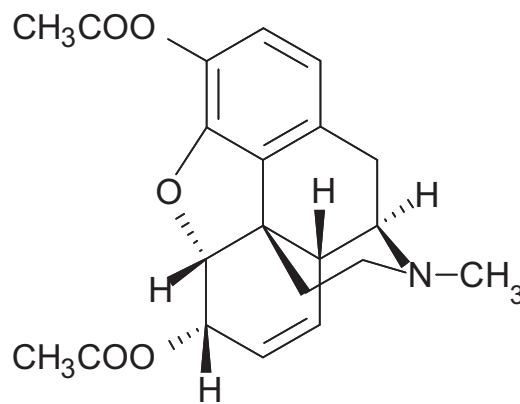

Heroin<smiles>C=CCN1C[C@H]2C=C[C@H](O)[C@@H]3Oc4c(O)ccc(c42)[C@H]1[C@@H]3C</smiles>

Nalorphine

Fig. 1. Heroin, acetylcodeine and their principal metabolites.

The aim of this work was the determination of heroin metabolites concentration, i.e. morphine and codeine (the latter deriving from the impurities present in "street heroin"), in different brain areas collected from two cases of death (Table 1) attributed to heroin overdose, in order to evaluate the distribution pattern of the metabolites throughout the brain. To this end a GC/MS technique was applied and the pretreatment of the sample, especially the deproteinization step, carefully studied to optimize the recovery of the analytes and the elimination of the interfering species.

\section{Experimental}

\subsection{Chemicals and reagents}

Morphine base, codeine base and nalorphine (Internal Standard, IS) were purchased from S.A.L.A.R.S. (Italy). Methanol of analytical grade, 5 -sulfosalicylic acid dihydrate, trichloroacetic acid and zinc sulfate were obtained from Sigma-Aldrich (Germany). Toluene, sodium tetraborate/hydrochloric acid pH 9 buffer solution and N-methyl-N-(trimethylsilyl)-trifluoroacetamide (MSTFA) were purchased from Fluka (Swiss), while dichloromethane and isopropyl alcohol from Prolabo (Italy). Ammonium sulfate was supplied from Carlo Erba (Italy) as well as glacial acetic acid. Water $(18.2 \mathrm{~m} \Omega / \mathrm{cm})$ was obtained with Milli-Q System (Millipore,
France). All reagents were of analytical grade and stored as required by their specifics.

\subsection{Sample preparation and deproteinization}

Post-mortem encephalic samples were collected from two fatalities attributed to heroin overdose, and were supplied by the Institute of Legal Medicine and Assurance of the University of Palermo. The samples were collected from six different encephalic areas: nuclei, pons, frontal lobe, bulb, occipital lobe and hippocampus.

Each sample was homogenized with a blender or ball mill, depending on the quantity of material, then the deproteinization of the biological matrix was performed applying five different procedures.

\subsubsection{Trichloroacetic acid}

$1 \mathrm{~mL}$ of trichloroacetic acid $10-15 \%(\mathrm{v} / \mathrm{v})$ was added to $500.0 \mathrm{mg}$ of homogenized brain previously added with $50 \mu \mathrm{L}$ of IS. After $5 \mathrm{~min}$ centrifugation, a limpid supernatant was separated and extracted by SPE.

\subsubsection{Zinc sulfate}

$1 \mathrm{~mL}$ of a mixture of methanol/zinc sulfate $0.2 \mathrm{M}(8: 2, \mathrm{v} / \mathrm{v})$ was added to $500.0 \mathrm{mg}$ of homogenized brain previously added with

Table 1

Overview of case studied.

\begin{tabular}{|c|c|c|c|}
\hline Case & Case history & Detected substances & Alcohol in blood $(\mathrm{g} / \mathrm{L})$ \\
\hline 1 & $\begin{array}{l}\text { 42-Year-old male, registered drug abuser, found dead } \\
\text { at his home }\end{array}$ & Morphine, codeine, dextromethorfan, nicotine, caffeine & 2.2 \\
\hline 2 & $\begin{array}{l}\text { 35-Year-old male, found dead in a public toilet, used } \\
\text { syringe found at scene }\end{array}$ & Morphine, codeine, paracetamol, nicotine, caffeine & 1.3 \\
\hline
\end{tabular}


$50 \mu \mathrm{L}$ of IS. After 5 min centrifugation, the organic supernatant was evaporated to dryness with a stream of $\mathrm{N}_{2}$ at $40^{\circ} \mathrm{C}$ and the residue was reconstituted in $4 \mathrm{~mL}$ of water and $2 \mathrm{~mL}$ of $\mathrm{pH} 9$ buffer solution before SPE.

\subsubsection{Ammonium sulfate}

$500.0 \mathrm{mg}$ of homogenized brain were treated with $50 \mu \mathrm{L}$ of IS and $3 \mathrm{~mL}$ of $\mathrm{H}_{2} \mathrm{O}$ and sonicated for $15 \mathrm{~min}$ before adding $1 \mathrm{~mL}$ of $\mathrm{HCl}$ $0.1 \mathrm{M}$. Then, $\left(\mathrm{NH}_{4}\right)_{2} \mathrm{SO}_{4}$ was added until saturation and the mixture was heated at $70^{\circ} \mathrm{C}$ for $30 \mathrm{~min}$. After cooling, centrifugation was carried out, but the biological matrix remained at the bottom of the tube, thus preventing the collection of the supernatant.

\subsubsection{5-Sulfosalicylic acid}

$200 \mathrm{mg}$ of 5-sulfosalicylic acid were added to $500.0 \mathrm{mg}$ of homogenized brain previously added with $50 \mu \mathrm{L}$ of IS and $1 \mathrm{~mL}$ of $\mathrm{H}_{2} \mathrm{O}$. After 5 min centrifugation, a limpid supernatant was separated and extracted by SPE.

\subsubsection{Ultrasonic bath}

$500.0 \mathrm{mg}$ of brain previously added with $4 \mathrm{~mL}$ of water, $2 \mathrm{~mL}$ of $\mathrm{pH} 9$ buffer solution and $50 \mu \mathrm{L}$ of IS were sonicated for $15 \mathrm{~min}$ at room temperature. After 5 min centrifugation, a limpid supernatant was separated and extracted with SPE.

\subsection{Extraction procedure}

The homogenized and deproteinized encephalic samples were centrifugated at $4000 \mathrm{rpm}$ for $5 \mathrm{~min}$ and extracted using Bond Elut-LRC Certify Solid Phase Extraction cartridges (Varian, CA, USA) with a Varian vacuum manifold (Varian, CA, USA). Cartridges were first conditioned with $2 \mathrm{~mL}$ of methanol and $2 \mathrm{~mL}$ of $\mathrm{pH} 9$ buffer solution. Brain supernatants were loaded and allowed to absorb with gravity flow. The columns were washed with $2 \mathrm{~mL}$ of water, $3 \mathrm{~mL}$ of $1 \mathrm{M}$ hydrochloric acid and $0.5 \mathrm{~mL}$ of methanol. The analytes were then eluted with $2 \times 1 \mathrm{~mL}$ of the elution solvent (dichloromethane:isopropyl alcohol:ammonium hydroxide, $8: 2: 0.2)$.

\subsection{Chromatography}

The extracts were evaporated to dryness under a stream of nitrogen at $40^{\circ} \mathrm{C}$ and derivatized with $50 \mu \mathrm{L}$ of a mixture MSTFA/toluene (1:4) at $70^{\circ} \mathrm{C}$ for $30 \mathrm{~min}$. Then GC/MS analyses were performed on a GC 6890 Plus with Mass Selective Detector and autosampler 6890, data were handled with a MSD Chemstation D.03.00 software (Agilent Technologies); chromatographic separation was carried out on a DB-5MS inert capillary column (30 $\mathrm{m} \times 0.25 \mathrm{~mm}$ i.d., $0.25 \mu \mathrm{m}$ film thickness, J.\&W. Scientific).

The GC/MS system was operated under the following conditions: injection temperature $280^{\circ} \mathrm{C}$ (splitless mode; $0.25 \mathrm{~min}$ splitless time); interface transfer line $280^{\circ} \mathrm{C}$; ion source $230^{\circ} \mathrm{C}$; initial column temperature $70^{\circ} \mathrm{C}$. Temperature was subsequently increased to $180^{\circ} \mathrm{C}$ at a rate of $40^{\circ} \mathrm{C} / \mathrm{min}$, then increased to $300^{\circ} \mathrm{C}$ at a rate of $10^{\circ} \mathrm{C} / \mathrm{min}$ and finally held for additionally $5 \mathrm{~min}$. Helium was used as the carrier gas at a flow rate of $1.2 \mathrm{~mL} / \mathrm{min}$. MS analysis was performed in SCAN $(50 / 550 \mathrm{~m} / \mathrm{z})$ and SIM mode by a quadrupole mass detector operated in electron ionization mode, the beam energy being $70 \mathrm{eV}$. Injection volume was $1 \mu \mathrm{L}$.

\subsection{Method validation}

Specificity, accuracy, precision and linearity, as well as LOD and LOQ, were evaluated analyzing working standard solutions prepared with morphine and codeine at different concentrations (10, $25,50,100,250,500$ and $1000 \mathrm{ng}$ tot) and nalorphine as Internal
Table 2

Qualifier positive ions and retention times for derivatized morphine, codeine and nalorphine.

\begin{tabular}{lll}
\hline Analyte & $\begin{array}{l}\text { Retention time } \\
(\mathrm{min})\end{array}$ & Positive ions $(\mathrm{m} / \mathrm{z})_{\text {relative intensity }}$ \\
\hline Codeine-TMS & 11.99 & $371_{100}, 314_{21}, 343_{20}$ \\
Morphine-2TMS & 12.35 & $429_{100}, 414_{52}, 401_{33}$ \\
Nalorphine-2TMS (IS) & 13.30 & $455_{100}, 440_{44}, 414_{53}$ \\
\hline
\end{tabular}

Standard. Particularly, $100 \mu \mathrm{L}$ of the working standard solutions $(0.1,0.25,0.5,1.0,2.5,5.0$ and $10.0 \mu \mathrm{g} / \mathrm{mL})$ were put in seven tubes, evaporated to dryness and then added with $500.0 \mathrm{mg}$ of blank brain.

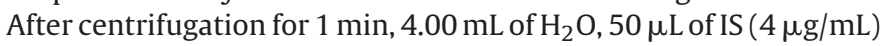
and $2 \mathrm{~mL}$ of $\mathrm{pH} 9$ buffer solution were added.

Analytes retention times and their characteristic ions $(\mathrm{m} / \mathrm{z})$ used for GC/MS identification and quantification are listed in Table 2.

For quantitative analyses the following ions were monitored: $\mathrm{m} / \mathrm{z} 371$ for codeine, $\mathrm{m} / \mathrm{z} 429$ for morphine and $\mathrm{m} / \mathrm{z} 455$ for nalorphine.

The quantification of the two drugs was based on the response factor RR, defined as: $\mathrm{RR}=\left(A_{\text {analyte }} / A_{\mathrm{IS}}\right) / C_{t}$. Where $A_{\text {analyte }}$ and $A_{\mathrm{IS}}$ are, respectively, the peak area of the analyte and the peak area of the IS and $C_{t}$ is the analyte concentration in the working standard solution expressed as total ng of analyte. The response factor was calculated for all the working standard solutions described above and the averaged $R R_{\text {medium }}$ was considered for the estimation of drugs concentration in brain specimens.

\section{Results and discussion}

\subsection{Method development}

Since brain is a complex matrix, we had to face several problems to obtain a homogenous and representative specimen with a good recovery of the analytes. To this end it was necessary to develop a suitable sample pretreatment before SPE, in order to minimize interfering species and optimize recovery.

After homogenization, each sample was submitted to a deproteinization procedure. Five methods were tested, whose comparison was based not only on the best results in terms of recovery, but also on the easy handling and required time.

The pretreatment with ammonium sulfate was the most complex and time-consuming. As a matter of fact, this procedure required several steps that increased the time of analysis; moreover, despite the last step in the centrifuge, the matrix was not completely deposited at the bottom of the tube, thus making difficult the recovery the supernatant, which often showed matrix residues, that could clog the pores of the sorbent extraction columns.

The method with zinc sulfate and methanol was also dismissed, because of the increasing time of analysis due to the evaporation of the solvent.

To compare the five deproteinization procedures, beyond practical reasons, we evaluated the recovery of morphine and codeine analyzing five different samples from the same homogenated brain area belonging to a real case of heroin fatality. Each sample was added with $50 \mu \mathrm{L}$ IS $(4 \mu \mathrm{g} / \mathrm{mL})$ and submitted to the five types of deproteinization. Once extracted and analyzed by GC/MS, we compared the ratios of the analyte areas and of the internal standard areas $\left(\mathrm{RA}=A_{\text {analyte }} / A_{\mathrm{IS}}\right)$ taking into account the amount of the biological matrix. Internal standard added before sample preparation provided an element of control of the analytical process because it minimized the variability factors due to instrumental analysis and loss of sample. Results are shown in Table 3. 
Table 3

Deproteinization methods and analytes recoveries.

\begin{tabular}{|c|c|c|c|c|}
\hline Sample & Deproteinization & Sample (g) & RAmorphine (g) & RAcodeine $(\mathrm{g})$ \\
\hline 1 & Trichloroacetic acid 15\% (v/v) & 0.5040 & 0.3457 & 0.0700 \\
\hline 2 & Zinc sulfate and methanol & 0.5012 & 0.3557 & 0.1611 \\
\hline 3 & Ammonium sulfate & 0.5230 & 0.3225 & 0.2508 \\
\hline 4 & 5-Sulfosalicylic acid & 0.5107 & 0.3029 & 0.1482 \\
\hline 5 & Ultrasonic bath & 0.5164 & 0.4490 & 0.2849 \\
\hline
\end{tabular}

As evident, the ultrasonic bath led to the best results in terms of RA/g, both for morphine and codeine. Furthermore, this technique was definitely faster than the others, so it was applied for the analysis of all the samples under investigation. Once established the best deproteinization method, the influence of the time of sonication on the recovery of the analytes was evaluated. Comparable results were obtained by increasing the sonication time up to $60 \mathrm{~min}$ (Table 4), so that a time of $15 \mathrm{~min}$ was chosen, in order to shorten the time of analysis.

For every brain area only one sampling was carried out because, as demonstrated by Stimpfl et al. [4], the distribution of drugs of abuse within each cerebral area is homogeneous and only one specimen is sufficient to represent the whole part.

Another point we had to assess was the amount of brain to weigh for each specimen. We prepared three samples from the same homogenated brain, the first sample of approximately $200 \mathrm{mg}$, the second of approximately $500 \mathrm{mg}$ and the third of about $1000 \mathrm{mg}$; we concluded that the optimum amount to use was $500 \mathrm{mg}$, since this quantity was representative of the matrix and analyte concentrations were above the limit of quantification.

After the pretreatment step, samples were submitted to SPE, derivatization and analysis by GC/MS, in the conditions described in Sections 2.3 and 2.4 .

\subsection{Method validation}

\subsubsection{Specificity}

Specificity was assessed by extracting control blank brain samples in each validation run. The lack of interfering peaks at the same analyte retention times was considered as an acceptable selectivity.

\subsubsection{Linearity}

The linearity of the response of GC/MS analysis was checked for codeine and morphine by plotting drug/internal standard peak area ratios versus the total amount of drug in the standard solutions, in the interval 10-1000 ng. Calibration curves showed good correlation coefficients (Fig. 2) for both analytes over the whole range.

\subsubsection{Accuracy}

Accuracy was expressed as the recovery (\%REC) evaluated by analyzing in triplicate six standard solutions of morphine ranging from 25.0 to $1000.0 \mathrm{ng}_{\text {tot }}$ and seven standard solutions of codeine ranging from 10.0 to $1000.0 \mathrm{ng}_{\text {tot }}$ \%REC was calculated according to: \% REC $=\left[A_{\text {analyte }} /\left(A_{\mathrm{IS}} \mathrm{RR}_{\text {med }} C_{t}\right)\right] \times 100$. Where $C_{t}$ is the total amount of analyte in the standard solution and $R_{\text {medium }}$ is defined in Section 2.5 .

The averaged results of the recovery studies for morphine and codeine are reported in Table 5.

Table 4

Influence of the sonication time on the recovery of the analytes.

\begin{tabular}{lllll}
\hline Sample & Time $(\mathrm{min})$ & Sample $(\mathrm{g})$ & RAmorphine $(\mathrm{g})$ & RAcodeine $(\mathrm{g})$ \\
\hline 1 & 15 & 0.5082 & 0.3789 & 0.3080 \\
2 & 30 & 0.5076 & 0.3349 & 0.2907 \\
3 & 60 & 0.5053 & 0.3114 & 0.2828 \\
\hline
\end{tabular}

Table 5

Accuracy of the method.

\begin{tabular}{lccc}
\hline Samples & \%REC & SD & \%RSD \\
\hline $\begin{array}{l}\text { Morphine: ACCURACY } \\
\begin{array}{l}18 \\
\text { Codeine: ACCURACY }\end{array} \\
\quad 100.1\end{array}$ & 6.39 & 6.38 \\
21 & 101.7 & 16.15 & 15.87 \\
\hline
\end{tabular}

\subsubsection{Precision}

The same standard solutions were analyzed in triplicate during three different days (I, II and III) in order to evaluate the precision of the method. The RR value was calculated for every standard solution and the medium response ratios $\left(R R_{\text {med }}\right)$ are reported in Table 6. Data obtained demonstrate an adequate reproducibility.

\subsection{5. $L O D$ and $L O Q$}

Limit of detection (LOD) and limit of quantitation (LOQ) were also evaluated. A series of decreasing concentrations of drugfortified homogenized brain samples was analyzed. LOD was determined to be the lowest analyte concentration with a $\mathrm{S} / \mathrm{N}$ ratio of at least 3 and resulted $10 \mathrm{ng}$ for morphine and $5 \mathrm{ng}$ for codeine, while LOQ was defined as the lowest concentration with a $\mathrm{S} / \mathrm{N}$ ratio of at least 10 at which the values of accuracy and precision had a coefficient of variation below $15 \%$. The LOQ was $25 \mathrm{ng}$ for morphine and $10 \mathrm{ng}$ for codeine and was calculated by analyzing standard solutions of morphine $25 \mathrm{ng}_{\text {tot }}$ and codeine $10 \mathrm{ng}_{\text {tot }}$ during 3 days (Table 7).

\subsection{Analysis of brain areas}

The validated method was applied to the analysis of six different brain areas: hippocampus, frontal lobe, occipital lobe, nuclei, bulb

Table 6

Precision of the method.

\begin{tabular}{|c|c|c|c|c|c|}
\hline $\mathrm{ng}_{\text {tot }}$ & RR I & RR II & RR III & & \\
\hline \multicolumn{6}{|c|}{ Morphine: PRECISION } \\
\hline 25.0 & 0.0120 & 0.0122 & 0.0117 & & \\
\hline 50.0 & 0.0107 & 0.0117 & 0.0109 & & \\
\hline 100.0 & 0.0099 & 0.0119 & 0.0101 & & \\
\hline 250.0 & 0.0103 & 0.0123 & 0.0104 & & \\
\hline 500.0 & 0.0103 & 0.0106 & 0.0107 & & \\
\hline 1000.0 & 0.0107 & 0.0110 & 0.0107 & & \\
\hline $\mathrm{RR}_{\text {med }}$ & 0.0106 & 0.0116 & 0.0108 & $\mathrm{RR}_{\text {med }}$ & 0.0110 \\
\hline$\pm \mathrm{SD}$ & 0.0007 & 0.0007 & 0.0006 & $\pm \mathrm{SD}_{\text {med }}$ & 0.0007 \\
\hline$\%$ RSD & 7.04 & 5.75 & 6.02 & $\% \mathrm{RSD}_{\text {med }}$ & 6.06 \\
\hline \multicolumn{6}{|c|}{ Codeine: PRECISION } \\
\hline 10.0 & 0.0402 & 0.0408 & 0.0484 & & \\
\hline 25.0 & 0.0444 & 0.0452 & 0.0328 & & \\
\hline 50.0 & 0.0406 & 0.0305 & 0.0349 & & \\
\hline 100.0 & 0.0324 & 0.0362 & 0.0354 & & \\
\hline 250.0 & 0.0303 & 0.0337 & 0.0423 & & \\
\hline 500.0 & 0.0307 & 0.0319 & 0.0324 & & \\
\hline 1000.0 & 0.0309 & 0.0347 & 0.0309 & & \\
\hline $\mathrm{RR}_{\text {med }}$ & 0.0356 & 0.0361 & 0.0367 & $\mathrm{RR}_{\text {med }}$ & 0.0361 \\
\hline$\pm \mathrm{SD}$ & 0.0059 & 0.0052 & 0.0063 & $\pm \mathrm{SD}_{\text {med }}$ & 0.0058 \\
\hline \%RSD & 16.62 & 14.71 & 17.23 & $\% \mathrm{RSD}_{\text {med }}$ & 16,05 \\
\hline
\end{tabular}



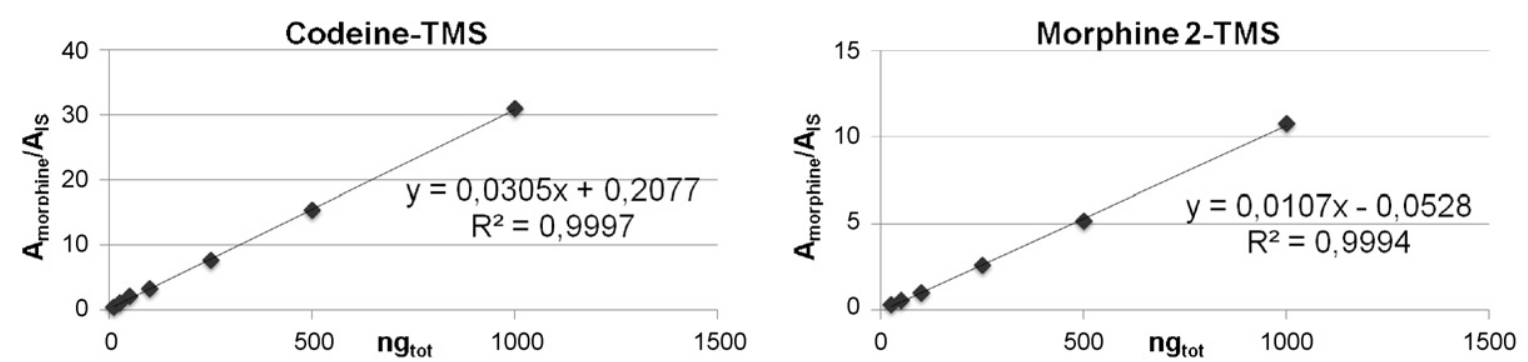

Fig. 2. Linearity of morphine and codeine.

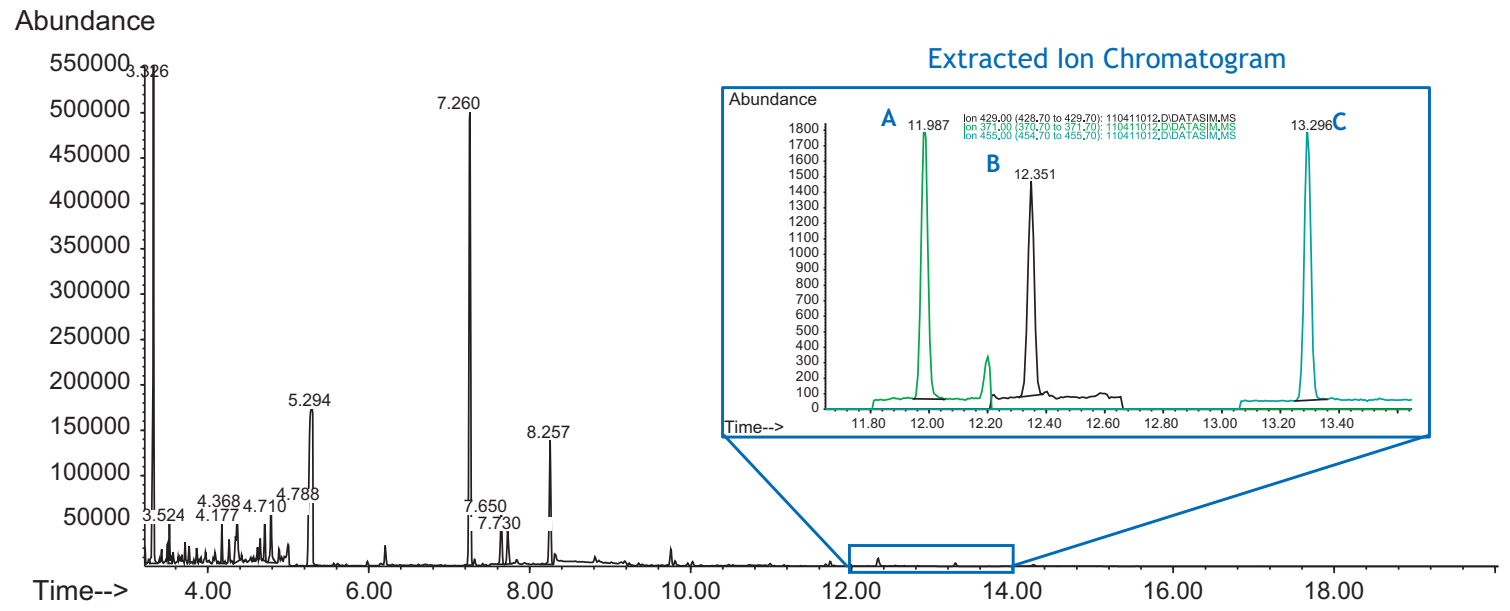

Fig. 3. SIM chromatogram of a specimen of case 2-(NUCLEI): (A) codeine-TMS; (B) morphine-2TMS; (C) IS.

Table 7

LOQ values.

\begin{tabular}{llllr}
\hline & $\mathrm{ng}_{\text {tot }}$ & $\mathrm{RR}_{\text {med }}$ & $\pm \mathrm{SD}$ & \%RSD \\
\hline Morphine & 25.0 & 0.0120 & 0.0003 & 2.10 \\
Codeine & 10.0 & 0.0431 & 0.0046 & 10.60 \\
\hline
\end{tabular}

Table 8

Concentrations of drugs in case 1.

\begin{tabular}{lcl}
\hline Brain areas & Morphine $(\mathrm{ng} / \mathrm{g})$ & Codeine $(\mathrm{ng} / \mathrm{g})$ \\
\hline Hippocampus & 106 & 34 \\
Occipital lobe & 71 & 32 \\
Bulb & 75 & 38 \\
Frontal lobe & 85 & 29 \\
Pons & 85 & 32 \\
Nuclei & 88 & 31 \\
\hline
\end{tabular}

and pons, taken from two cases of heroin fatalities (Table 1), to evaluate brain distribution pattern of morphine and codeine.

A representative chromatogram obtained for the analysis of Case 2 nuclei is reported in Fig. 3.

The results demonstrated that morphine and codeine were homogeneously distributed in all the areas analyzed (Tables 8 and 9,

\section{Table 9}

Concetrations of drugs in case 2 .

\begin{tabular}{lll}
\hline Brain areas & Morphine $(\mathrm{ng} / \mathrm{g})$ & Codeine $(\mathrm{ng} / \mathrm{g})$ \\
\hline Hippocampus & 129 & 13 \\
Occipital lobe & 181 & 24 \\
Bulb & 114 & 14 \\
Frontal lobe & 147 & 16 \\
Pons & 159 & 25 \\
Nuclei & 149 & 28 \\
\hline
\end{tabular}

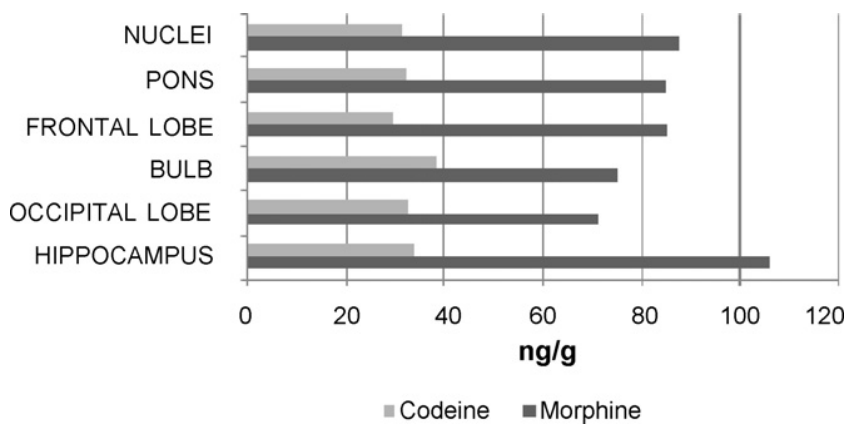

Fig. 4. Distribution of the analytes in case 1.

Figs. 4 and 5) and the analyte concentration detected in the basal ganglia (nuclei), which is the area generally collected during an autopsy, was representative of the whole brain, showing an intermediate concentration of morphine and codeine in both fatalities.

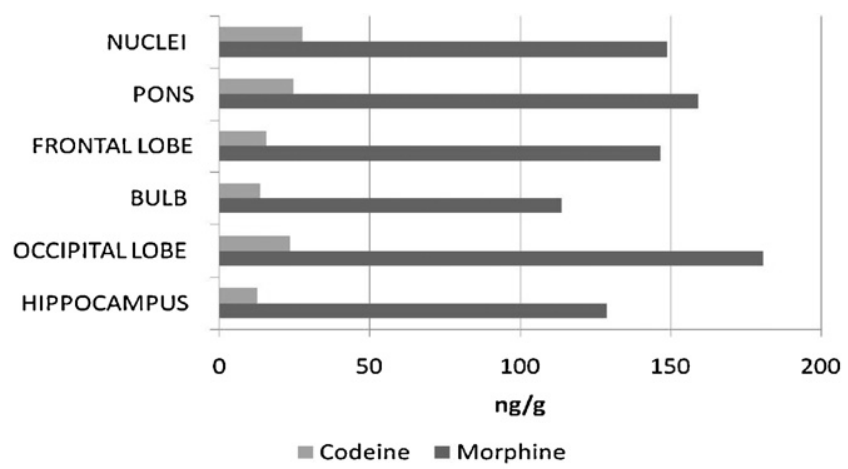

Fig. 5. Distribution of the analytes in case 2. 


\section{Conclusions}

A simple and reliable GC/MS method for the quantification of heroine metabolites morphine and codeine in brain has been developed and validated. Specificity, linearity, accuracy, precision, LOD and LOQ were examined for the analytes and found satisfactory.

The pretreatment of the biological sample, especially the deproteinization procedure was studied in order to optimize the recovery of the analytes and the elimination of the interfering species in a complex matrix such as brain. Five methods were tested: pretreatment with trichloroacetic acid, ammonium sulfate, zinc sulfate, 5-sulfosalicylic acid and ultrasonic bath. The ultrasonic bath led to the best results in terms of recovery, both for morphine and codeine and was definitely faster and simpler than the others, so it was applied for the analysis of all the samples under investigation. After the pretreatment step, samples were submitted to SPE, derivatization and analysis by GC/MS.

The method was applied to the analysis of six brain area specimens coming from two heroin-related fatalities. Results showed that there was no evidence of accumulation of heroin metabolites in a particular brain area and that the analytes concentration in the nuclei was representative of morphine and codeine levels in brain tissue.

\section{References}

[1] E.L. Way, J.M. Young, J.W. Kemp, Metabolism of heroin and its pharmacologic implications, Bull. Narc. 17 (1965) 25-33.

[2] E.J. Rook, A.D.R. Huitema, W. Van den Brink, J.M. Van Ree, J.H. Beijnen, Pharmacokinetics and pharmacokinetic variability of heroin and its metabolites: review of the literature, Curr. Clin. Pharmacol. 1 (2006) 109-118.

[3] R. Lowe, A. Barnes, F. Lehrmann, T. Hyde, M. Herman, A validated positive chimical ionization GC/MS method for the identification and quantification of amphetamines, opiates, cocaine, and metabolites in human post mortem brain, J. Mass Spectrom. 41 (2006) 175-184.

[4] T. Stimpfl, S. e Reichel, Distribution of drugs within specific regions of the human brain, Forensic Sci. Int. 170 (2007) 179-182.

[5] B.A. Goldberger, E.J. Cone, T.M. Grant, Y.H. Caplan, B.S. Levine, J.E. Smialek, Disposition of heroin and its metabolites in heroin related deaths, J. Anal. Toxicol. 18 (1994) 22-28.

[6] F. Moriya, Y. Hashimoto, Post-mortem stability of cocaine and cocaethylene in blood and tissue of human and rabbits, J. Forensic Sci. 41 (1996) 612-616.

[7] W.R. Sawyer, R.B. Forney, Post-mortem disposition of morphine in rats, Forensic Sci. Int. 38 (1988) 259-273.

[8] A.J. Jenkins, Drug Testing in Alternate Biological Specimens, Humana Press, Inc., 2008, pp. 157-180.

[9] E.M. Pare, J.R. Monforte, R.J. Thibert, Morphine concentrations in brain tissue from heroin-associated death, J. Anal. Toxicol. 8 (1984) 213-216.

[10] P. Kintz, P. Mangin, A.A. Lugnier, A.J. Chaumont, Toxicological data after heroin overdose, Hum. Toxicol. 8 (1989) 487-489.

[11] F. Moriya, Y. Hashimoto, Distribution of free and conjugated morphine in body fluids and tissue in fatal heroin overdose: is conjugated morphine stable in post-mortem specimens? J. Forensic Sci. 42 (1997) 736-740.

[12] D. Reed, V.R. Spieler, R.H. Cravey, Two cases of heroin-related suicide, Forensic Sci. 9 (1977) 49-52.

[13] J. Scheurer, C.M. Moore, Solid-phase extraction of drugs from biologica tissues-a review, J. Anal. Toxicol. 16 (1992) 264-269.

[14] A. Klingmann, G. Skopp, I. Pedal, L. Poetsch, R. Aderjan, Distribution of morphine and morphine glucuronides in body tissues and body fluids. Postmortem findings in short survival time, Arch. Kriminol. 206 (2000) 38-49.

[15] M. Freiermuth, J-C Plasse, Determination of morphine and codeine in plasma by HPLC following solid phase extraction, J. Pharm. Biomed. Anal. 15 (1997) 759-764.

[16] D.M. Shakleya, M.A. Huestis, Simultaneous quantification of nicotine, opioids, cocaine and metabolites in human fetal post-mortem brain by liquid chromatography tandem mass spectrometry, Anal. Bioanal. Chem. 393 (2009) 1957-1965.

[17] D. Reed, Comparison of spectrofluorimetric and GC/MS procedures for the quantitation of morphine in blood and brain, Clin. Toxicol. 14 (1979) $160-180$.

[18] V.R. Spiehler, R. Brown, Unconjugated morphine in blood by radioimmunoassay and gas chromatography/mass spectrometry, J. Forensic Sci. 32 (1987) 906-916. 